\title{
O ARTIGO 43 DO CÓDIGO DE DEFESA DO CONSUMIDOR E SUAS DIVERSAS INTERPRETAÇÕES QUANTO À PERMANÊNCIA DE INSCRIÇÕES NEGATIVAS
}

\begin{abstract}
João Fernando Fank ${ }^{1}$ Eduardo Schmidt Jobim ${ }^{2}$

RESUMO: Diversas interpretações conflitantes surgiram sobre o parágrafo $5^{\circ}$ do art. 43 do Código de Defesa do Consumidor desde sua promulgação. Gerou-se uma grande polêmica acerca do prazo prescricional referido no citado dispositivo, que determina o termo máximo de manutenção dos registros negativos de inadimplentes em cadastros especializados - SPCs. Busca-se, neste artigo, elucidar a questão com meticulosa análise das teorias surgidas sobre o tema.

PALAVRAS-CHAVE: Código de Defesa do Consumidor. Serviços de Proteção ao Crédito. Prescrição. Títulos de crédito.
\end{abstract}

\section{The different interpretations of the Consumer's Defense Code's article 43.}

ABSTRACT: Several clashing interpretations have arisen over the fifth paragraph of Consumer's Defense Code's article 43 since it's promulgation. Great polemics raged about the prescriptional term cited on such dispositive, which specificates the maximum upkeep of the negative data about debtors in specialized cadastres SPCs. In this articles, the objective is to clarify the matter through careful analysis of the existent theories.

\section{Introdução}

O SPC - Serviço de Proteção ao Crédito - consiste em um banco de dados privado, em que constam informações de crédito, com caráter público. É organizado geralmente pelas câmaras de dirigentes lojistas, associações comerciais ou outras entidades que representam comerciantes e empresários, que trocam informações relativas a todo o território nacional por meio de um sistema chamado RENIC, rede nacional de informações comerciais. Assim como o SPC existem outros bancos de dados privados que têm fins semelhantes ou análogos.

O objetivo do SPC é agilizar o sistema de crédito, assim como fornecer maior segurança às empresas, protegendo as transações comerciais. Para tanto, armazena dados relativos aos inadimplentes, fornecendo-as a seus associados. No exercício desta atividade, os SPCs se submetem às normas do Código de Defesa do Consumidor [Lei no 8.078/90]. A inscrição neste banco de dados normalmente advém de dívidas de comércio, apesar de cada associação ter relativa liberdade para determinar, através de seus regulamentos ou estatutos, os motivos exatos que podem levar ao cadastramento no SPC. A pessoa cadastrada junto ao SPC

\footnotetext{
${ }_{1}^{1}$ Acadêmico de Direito na Universidade Federal de Santa Maria.

${ }^{2}$ Advogado. Graduado em Direito pela UFSM.

ISSN 1981-3694

(C) 2008. Departamento de Direito da UFSM. Todos os direitos reservados.
} 
pode - e deve - ter acesso às informações pertinentes a sua "negativação". Se, no entanto, quiser a informação por escrito, entende-se licito à entidade mantenedora do SPC cobrar uma taxa a título de custos de emissão.

A fim de buscar proteção contra devedores inadimplentes, o credor tem o direito de protestar o título não pago, cadastrar o nome do devedor em órgãos de restrição ao crédito, como SPC, SERASA, etc., além, é claro, de ajuizar ação para cobrar o valor devido. Pequenas empresas dependem muito das garantias oferecidas por estes bancos de dados, como forma de permitir sua competitividade frente a empresas de grande porte. De outro modo, a recorrência dos inadimplementos acabaria por levar à falência essas companhias que não têm outros meios de recuperar o lucro perdido em função destes.

Ao disponibilizar ao público este tipo de informação, sobremaneira delicada, os SPCs devem observar que se deve evitar constranger o devedor, como depreende da leitura dos seguintes artigos:

Art. 42. Na cobrança de débitos, o consumidor inadimplente não será exposto a ridículo, nem será submetido a qualquer tipo de constrangimento ou ameaça.

(...)

Art. 71. Utilizar, na cobrança de dívidas, de ameaça, coação, constrangimento físico ou moral, afirmações falsas incorretas ou enganosas ou de qualquer outro procedimento que exponha o consumidor, injustificadamente, a ridículo ou interfira com seu trabalho, descanso ou lazer:

Pena: Detenção de três meses a um ano e multa.

De fato, José Tavares Guerreiro, descreveu a conjuntura de fatores que levaram os responsáveis a enfrentar o desafio da normatização dos bancos de dados:

\begin{abstract}
A extraordinária rapidez com que os bancos de dados podem elaborar perfis de informação dos indivíduos (no assim dito "tempo zero"), a possibilidade de desvio de finalidades na utilização dos próprios dados informativos e a falibilidade dos processos informáticos constituem potencial ameaça aos direitos da personalidade, na medida em que produzem (ou podem produzir) situações constrangedoras, das quais a pessoa só pode se liberar mediante meios modernos de tutela (entre os quais os agora previstos), dado que as soluções tradicionais se mostram ineficazes para garantir a sua segurança e tutelar adequadamente seus interesses. [GUERREIRO, 1996, p. 142]
\end{abstract}

Deste modo, o diploma consumerista regula a atividade de tais cadastros a bem de resguardar os direitos informados pelos supramencionados artigos. Dispõe, assim, que: 


\begin{abstract}
Art. 43. O consumidor, sem prejuízo do disposto no art. 86, terá acesso às informações existentes em cadastros, fichas, registros e dados pessoais e de consumo arquivados sobre ele, bem como sobre as suas respectivas fontes.

$\S 1^{\circ}$ Os cadastros e dados de consumidores devem ser objetivos, claros, verdadeiros e em linguagem de fácil compreensão, não podendo conter informações negativas referentes a período superior a cinco anos.

$\S 2^{\circ}$ A abertura de cadastro, ficha, registro e dados pessoais e de consumo deverá ser comunicada por escrito ao consumidor, quando não solicitada por ele.

$\S 3^{\circ} \mathrm{O}$ consumidor, sempre que encontrar inexatidão nos seus dados e cadastros, poderá exigir sua imediata correção, devendo o arquivista, no prazo de cinco dias úteis, comunicar a alteração aos eventuais destinatários das informações incorretas. $\S 4^{\circ}$ Os bancos de dados e cadastros relativos a consumidores, os serviços de proteção ao crédito e congêneres são considerados entidades de caráter público. $\S 5^{\circ}$ Consumada a prescrição relativa à cobrança de débitos do consumidor, não serão fornecidas, pelos respectivos Sistemas de Proteção ao Crédito, quaisquer informações que possam impedir ou dificultar novo acesso ao crédito junto aos fornecedores.
\end{abstract}

É justamente em relação ao parágrafo $5^{\circ}$ do citado artigo que se formou uma polêmica, referente ao lapso temporal pelo qual tais registros podem perdurar no caso de inscrições feitas a partir de títulos de crédito - cheques. É nesse âmbito que faremos uma análise mais aprofundada.

\title{
2. Das disposições do CDC sobre a manutenção de registros negativos
}

O Código de Defesa do Consumidor é bastante claro em afirmar que o máximo tempo admitido para registros negativos em bancos de dados é de cinco anos, como já restou referido no $\S 1^{\circ}$ do art. 43.

Todavia, a polêmica que se gera nos tribunais do país está intimamente relacionada à interpretação do parágrafo quinto do supramencionado artigo que informa mais uma restrição a essa permanência:

$\S 5^{\circ}$ Consumada a prescrição relativa à cobrança de débitos do consumidor, não serão fornecidas, pelos respectivos Sistemas de Proteção ao Crédito, quaisquer informações que possam impedir ou dificultar novo acesso ao crédito junto aos fornecedores.

Depreende-se da leitura desse dispositivo que os registros não podem ser mantidos se extinta a pretensão do credor de cobrar o débito. Disso decorre a necessidade de analisar mais profundamente o instituto da prescrição.

ISSN 1981-3694

(C) 2008. Departamento de Direito da UFSM. Todos os direitos reservados. 


\section{Da prescrição}

Informa Francisco Amaral:

Desde a concepção do ser humano, o tempo influi nas relações jurídicas de que o indivíduo participa. É ele o personagem principal do instituto da prescrição. Nesse campo, a interferência desse elemento é substancial, pois existe interesse da sociedade em atribuir juridicidade àquelas situações que se prolongam no tempo. [AMARAL, 2000, p. 555]

O instituto da prescrição é necessário para que haja tranqüilidade na ordem jurídica, pela consolidação de todos os direitos. Para Câmara Leal, a prescrição se define como "a extinção de uma ação ajuizável, em virtude da inércia de seu titular durante um certo lapso de tempo, na ausência de causas preclusivas de seu curso" [LEAL, 1939, p. 54]. Significa dizer que a prescrição torna inexigível um direito depois de decorrido um certo lapso temporal. A fim de garantir a já citada segurança jurídica também aos inadimplentes, o CDC afirma que registros negativos não serão mantidos no SPC se a dívida a que eles se referem não for mais exigível, se isso se der em menos de cinco anos, tempo limite. A matéria foi, inclusive, sumulada, consoante se verifica a Súmula $n^{\circ} 8$ das Turmas Recursais dos Juizados Especiais do TJ-RS:

SÚMULA Nº8 SPC - CANCELAMENTO DE INSCRIÇÃO NEGATIVA. - A inscrição negativa do consumidor, perante o SPC, será cancelada após o decurso do prazo de 05 anos, independentemente da espécie de título de crédito representativo do débito, ressalvadas as hipóteses de prescrição da ação de cobrança em prazo inferior.

Resta, portanto, definir em quanto tempo ocorre a prescrição relativa àquelas inscrições feitas a partir de cheques, ou seja, depois de quanto tempo o débito torna-se inexigível. E nesse sentido, encontramos três entendimentos totalmente diversos sobre o assunto, que serão doravante estudados.

3.1 Da prescrição em 7 ou 8 meses

ISSN 1981-3694

(C) 2008. Departamento de Direito da UFSM. Todos os direitos reservados. 
Defendem alguns, com base no art. 59 da Lei do Cheque [Lei 7.357/85], que a prescrição da ação relativa à execução de cheques sem provisão de fundos transcorre em sete meses. Vejamos:

Art .33 O cheque deve ser apresentado para pagamento, a contar do dia da emissão, no prazo de 30 (trinta) dias, quando emitido no lugar onde houver de ser pago; e de 60 (sessenta) dias, quando emitido em outro lugar do País ou no exterior. [Lei 7.357/85 - Lei do Cheque]

Uma vez transcorridos os 30 ou 60 dias sem que a obrigação tenha sido satisfeita, estará violado o direito do credor, nascendo, portanto, a pretensão. Inicia-se, conseqüentemente, o transcurso da prescrição para a execução do título de crédito.

Art. 59 Prescrevem em 6 (seis) meses, contados da expiração do prazo de apresentação, a ação que o art. 47 desta Lei assegura ao portador. Parágrafo único A ação de regresso de um obrigado ao pagamento do cheque contra outro prescreve em 6 (seis) meses, contados do dia em que o obrigado pagou o cheque ou do dia em que foi demandado.

Considerando o disposto nesse artigo, correriam sete ou oito meses entre a data do cheque e a prescrição da ação de execução motivada por falta de pagamento. Concomitantemente, por conseguinte, entendem erroneamente alguns que deveria ocorrer a extinção dos registros negativos no SPC.

Atualmente, é difícil encontrar jurisprudência que sustente esse entendimento. Sendo [como já salientado] equivocado, não é mais aceito, por inúmeros motivos que serão analisados.

3.2 Da prescrição em 31 meses

À luz dos argumentos supracitados, vejamos o artigo 61 da Lei do Cheque:

Art. 61 A ação de enriquecimento contra o emitente ou outros obrigados, que se locupletaram injustamente com o não-pagamento do cheque, prescreve em 2 (dois) anos, contados do dia em que se consumar a prescrição prevista no art. 59 e seu parágrafo desta Lei.

ISSN 1981-3694

(C) 2008. Departamento de Direito da UFSM. Todos os direitos reservados. 
Ora, se a partir do momento em que restar consumada a prescrição da execução prevista no art. 59, sete ou oito meses depois da emissão do cheque, o titular deverá, pelo que determina a própria Lei do Cheque, ter dois anos para ajuizar ação contra o emitente, restando líquido e certo que o que prescreve ao final dos primeiros sete ou oito meses é ação de execução do cheque e não o direito de cobrar a dívida do referido título de crédito. Não é possível afirmar, portanto, que os registros do SPC devem ser eliminados uma vez transcorrido este período que o credor teria para executar o cheque. Entendem os defensores dessa tese que o título de crédito - cheque - prescreveria em dois anos e sete meses ou dois anos e oito meses [a soma do prazo prescricional da execução juntamente com o prazo para o ingresso da ação de enriquecimento ilícito contra o emitente ou outros obrigados, conforme se denota do próprio artigo 61 da Lei do Cheque]. Afirmam os que sustentam esta tese que deve ser esse o período máximo de manutenção dos registros negativos em bancos de restrição ao crédito. Em nossos tribunais é comum encontrar, em algumas Câmaras, aceitação de tal teoria em suas decisões, conforme citamos:

EMENTA: AÇÃO DE CANCELAMENTO DE REGISTRO. SPC. PRESCRIÇÃO. Possibilidade jurídica do pedido. Pleiteando a autora o cancelamento de registros em banco de dados, apontados há mais de três anos, não há impossibilidade jurídica do pedido, nos termos do art. 43 , $\S 5^{\circ}$, do CDC e Súmula n. 13 deste Tribunal. Apelação provida. Sentença desconstituída. [Apelação Cível No 70007476195, Décima Primeira Câmara Cível, Tribunal de Justiça do RS, Relator: Pedro Luiz Rodrigues Bossle, Julgado em 19/11/2003]

\subsection{Da prescrição em 5 anos}

Para entender esta tese, cabe uma elucidação sobre a natureza das inscrições no SPC, além de um olhar mais atento ao objetivo do legislador ao inscrever o parágrafo $5^{\circ}$ no art. 43 do Código de Defesa do Consumidor. Nos registros dos bancos negativos de crédito, constam obrigações não cumpridas, em sua grande maioria negócios jurídicos de compra e venda. Os cheques inscritos vêm a ser apenas prova do descumprimento dessas obrigações, e não o objeto do registro per se. Tendo isso em mente, vejamos o que dispõe o Código Civil:

Art. 206. Prescreve:

ISSN 1981-3694

(C) 2008. Departamento de Direito da UFSM. Todos os direitos reservados. 
(...)

$\S 5^{\circ}$ Em cinco anos:

I - A pretensão de cobrança de dívidas líquidas constantes de instrumento público ou particular;

(...)

Entenda-se, por "dívida líquida constante de instrumento público ou particular", também a decorrente de compra e venda e os demais contratos geralmente utilizados no comércio. Verificando-se que a ação de cobrança por esse tipo de dívida prescreve em cinco anos, não seria de se afirmar que é possível manter registros no SPC pelo mesmo período, quando delas decorrentes?

Necessário, ab initio, perscrutar qual agenda perseguia o legislador com o parágrafo $5^{\circ}$ do art. 43 do código consumerista. O objetivo é deveras claro, pois uma leitura mais atenta do dispositivo permite notar que sua função é apenas a de evitar que o consumidor continue sendo penalizado por um débito que já não mais pode ser cobrado. Importa, então, questionar: uma compra e venda "paga" com cheque sem fundos pode ser cobrada até quanto tempo depois de efetivada a transação? Pacífico que a prescrição fulminará a pretensão do credor apenas cinco anos após a data do negócio. Fica claro, deste modo, que as inscrições em cadastros restritivos de crédito deveriam perdurar por tais cinco anos, e não menos.

A título de exemplo: Caio vai a uma loja e compra um objeto, a ser pago em trinta dias, através de um carnê, em dinheiro. Não tendo saldado sua dívida com a loja, esta inscreve Caio no SPC. Este registro poderá ser mantido indiscutivelmente (uma vez que a loja enviará para a entidade responsável pelo SPC ao qual é associada, cópia do não pagamento do carnê ou do contrato), como vimos, por cinco anos. Entretanto, se Caio tivesse pagado sua compra com um cheque, que a loja credora descobre, mais tarde, não ter fundos, seria lógico afirmar que, nesse caso, o registro por ela efetuado no SPC só poderia perdurar por dois anos e sete meses ou ainda por sete ou oito meses?

Ilustremos a situação em mais um exemplo. Caio dá um cheque a Tício, que o utiliza para pagar uma compra efetuada em uma loja. Ao descobrir que o cheque não tem fundos, a loja deve inscrever Tício no SPC. O registro de Caio, que emitiu um título de crédito - cheque, poderia ser mantido no banco de dados por dois anos e sete meses, se a loja cadastrasse Caio no banco de dados. No caso, Caio teria tão somente uma obrigação cambiária com a loja, jamais uma obrigação contratual. O registro referente a Tício, por sua vez, deverá ser sempre 
mantido por cinco anos, já que está claro que ele realizou uma compra, obrigação contratual, e que a prescrição da ação contra ele se daria ao final deste período [o período que a loja tem para ajuizar uma ação de cobrança].

O que ocorre na maioria das inscrições constantes do SPC feitas a partir de cheques é que Caio e Tício são, em quase a totalidade dos casos, uma única pessoa [mesmo porque os comerciantes não têm por hábito aceitar cheques de terceiros como forma de pagamento]. Então, mesmo que o título de crédito - cheque - em si prescreva em 31 meses, a dívida decorrente da compra efetuada prescreve em cinco anos. O cheque, então, seria mera prova da obrigação não cumprida pelo devedor [descumprimento da obrigação contratual].

Recentemente, os tribunais pátrios têm passado a entender ser lícita a manutenção desses registros por cinco anos, e não meros trinta e um ou trinta e dois meses. O próprio Superior Tribunal de Justiça pacificou este entendimento. Para melhor ilustrar, citamos:

EMENTA: APELAÇÃO CÍVEL. CANCELAMENTO DE REGISTROS NO SPC. PRESCRIÇÃO. ART. 43, PARÁGRAFOS $1^{\circ}$ E $5^{\circ}$ DO CDC. PRAZO QÜINQÜENAL. A Câmara firmou posicionamento no sentido de que o prazo para cancelamento dos registros em bancos de dados é de cinco anos, por força do art. 43, parágrafos $1^{\circ}$ e $5^{\circ}$, do Código de Defesa do Consumidor, e não o de eventual ação cambial. Precedentes da Câmara e do STJ. Apelo improvido. [Apelação Cível No 70015757115, Décima Quinta Câmara Cível, Tribunal de Justiça do RS, Relator: Paulo Roberto Felix, Julgado em 20/12/2006]

EMENTA: APELAÇÃO CÍVEL. AÇÃO DE CANCELAMENTO DE REGISTRO. SPC. PRESCRIÇÃO. PRAZO QÜINQÜENAL. 1. Nos termos do art. $43, \S \S 1^{\circ}$ e $5^{\circ}$, da Lei $n^{\circ} 8.078 / 90$ e da Súmula $n^{\circ} 13$ deste Tribunal, o nome do devedor é excluído dos cadastros de proteção ao crédito depois de decorridos 05 (cinco) anos da inscrição, ou antes disso se houver ocorrido a prescrição da ação de cobrança. 2. O dies a quo desse prazo é a data do cadastramento, não o do vencimento da obrigação ou do título. 3. Não tendo havido o decurso do prazo de 05 (cinco) anos para nenhum dos registros, é regular sua manutenção. APELO DESPROVIDO. UNÂNIME. [Apelação Cível N No 70018849091, Nona Câmara Cível, Tribunal de Justiça do RS, Relator: Iris Helena Medeiros Nogueira, Julgado em 28/03/2007]

\section{Considerações finais}

Ante o que foi exposto, resta claro que a tese mais acertada é a que defende a manutenção dos registros por cinco anos. Isso se dá não apenas pelos motivos de direito já expostos, mas também pelo fato de que isso permite maior segurança ao comércio.

ISSN 1981-3694

(C) 2008. Departamento de Direito da UFSM. Todos os direitos reservados. 
Enquanto grandes redes comerciais são respaldadas por bancos, podendo praticar juros acima dos $12 \%$ fixados em lei como forma de recuperar os prejuízos causados por consumidores inadimplentes, pequenas empresas não têm tal prerrogativa. Sabemos, também, que o custo para promover ações judiciais para a cobrança dessas dívidas na maioria das vezes é muito superior ao da dívida em si, geralmente de valor reduzido. Igualmente, não é permitido a pessoas jurídicas [salvo microempresas] procurar os serviços dos Juizados Especiais Cíveis, muito mais baratos e céleres. Resta a essas empresas, portanto, buscar amparo no SPC e bancos de dados afins, que ensejam uma prevenção geral contra as perdas causadas por estas dívidas nunca resolvidas. De fato, a vasta maioria dos conveniados com estes cadastros restritivos de crédito são, como dita a lógica, microempresas e empresas de pequeno porte, mais carentes da proteção oferecida pelos SPCs.

Determinar um prazo tão pequeno, como pretendem os defensores da limitação de inscrições negativas advindas de cheques a 31 ou 32 meses, é condenar essas empresas a arcar com o enorme ônus causado por altos índices de inadimplemento, e muitas vezes até à falência, à revelia de todos os pressupostos de funcionamento em que se calca o nosso modelo de mercado, como nota Fábio Nusdeo:

\footnotetext{
Um outro pressuposto básico do sistema de mercado (...) vem a ser o da chamada atomização, isto é, o mercado para bem funcionar deve ser composto por um número razoavelmente elevado de compradores e vendedores em interação recíproca, e nenhum deles excessivamente grande ou importante. [NUSDEO, 2000, p. 149]
}

Ademais, a adoção de prazos tão curtos seria praticamente um incentivo ao não pagamento de dívidas, dada a ausência de consequiências causadas por esta prática. É possível notar, conseguintemente, por meio desta breve exposição, a importância da manutenção de registros negativos em bancos de restrição ao crédito e seus fundamentos jurídicos, assim como os benefícios trazidos por eles ao mercado.

\section{Referências Bibliográficas}


GUERREIRO, José Alexandre Tavares et. al., Comentários ao Código de Defesa do Consumidor, coordenação de José Cretella Júnior e René Ariel Dotti, Rio de Janeiro: Forense, 1996.

AMARAL, Francisco, Direito Civil. Rio de Janeiro: Renovar, 2000.

NUSDEO, Fábio, Curso de Economia: Introdução ao Direito Econômico. São Paulo: Saraiva, 2000.

LEAL, António Luiz da Câmara, Da Prescrição e da Decadência. São Paulo: Livraria Acadêmica, 1939. 